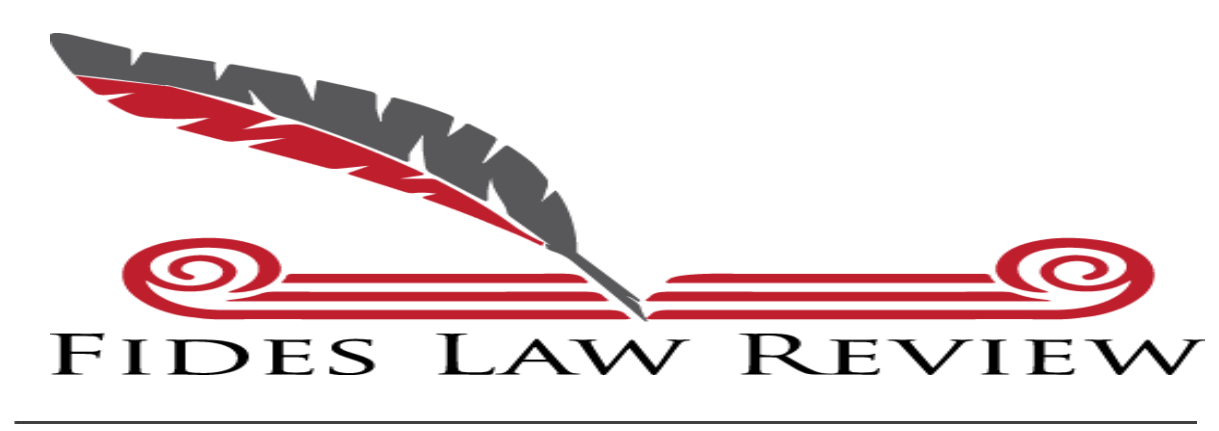

FIDES LAW REVIEW Dergisi Yıl:1, Sayı:1, Aralık 2018, s.7-16

\author{
Dr. Nilüfer BORAN-GÜNEYSU* \\ Stj. Av. Burak MEMiş ${ }^{*}$ * \\ BITCOIN VE İCRA HUKUKU
}

\title{
GíRiş
}

Bilişim teknolojisindeki gelişme, finans piyasalarını etkilemiş ve kredi kartları, elektronik para ${ }^{1}$, sanal para $^{2}$ veya kripto para ${ }^{3}$ gibi kavramlar hayatımıza girmiştir. 2008 yılında hayatımıza giren bitcoin, herkesin ilgisini çekmeyi başarmış ve kripto para piyasasının en çok yatırım alan üyesi haline gelmiştir. Bitcoinin yaygınlaşması ve insanlar tarafından kabulü, sorun ve tartışmaları da beraberinde getirmiştir. Rusya'dan Türkiye'ye yapılan bir buğday ticaretinde taşıma masrafı ödemesinin bitcoin ile yapıldığı ve böylelikle dünyada ilk kez bir navlun ücretinin bitcoin ile ödenmiş olduğu ifade edilmektedir ${ }^{4} .2017$ yılında bitcoin bir cinayetin nedenleri arasında gösterilmektedir ${ }^{5}$.

\footnotetext{
*Anadolu Üniversitesi Hukuk Fakültesi Medenî Usûl ve İcra-İflâs Hukuku Ana Bilim Dalı (nboran@anadolu.edu.tr).

** Istanbul Barosu (burakmemiss@gmail.com.tr).
}

\footnotetext{
${ }^{1}$ Elektronik para, Ödeme ve Menkul Kiymet Mutabakat Sistemleri, Ödeme Hizmetleri ve Elektronik Para Kuruluşları Hakkında Kanun gereğince, elektronik para ihraç eden kuruluş tarafından kabul fon karşılığı ihraç edilen, elektronik olarak saklanan, Kanun'da tanımlanan ödeme işlemlerini gerçekleştirmek için kullanılan ve elektronik para ihraç eden kuruluş dışındaki gerçek ve tüzel kişiler tarafından da ödeme aracı olarak kabul edilen parasal değer olarak tanımlanmaktadır (Selçuk, s. 67).

${ }^{2}$ Sanal para, dijital veya elektronik nitelikteki bir paradır; ancak sanal paranın temsil ettiği kâğıt para veya gerçeklik bulunmamaktadır (Selçuk, s. 67).

${ }_{3}^{3}$ Sanal paranın güvenlik için şifrelenmiş hali kripto para olarak nitelendirilmektedir (Selçuk, s. 68).

${ }^{4} \mathrm{http} / / / \mathrm{www}$.haberturk.com/turkiye-ye-bitcoin-ile-bugday-dunyada-bir-ilk-1808541-ekonomi (24.01.2018).

5 http://www.hurriyet.com.tr/bitcoin-cinayetinde-sok-detaylar-40582766 24.010.2018(24.01.2018).
} 


\section{BITCOIN VE İCRA HUKUKU}

Bitcoinin ekonomi ve para piyasaları kadar hukukun da gündeminde olan bir konudur. Bitcoin, ceza veya vergi hukuku ile doğrudan ilişkili olduğu gibi borçlar, yargılama ve icra hukuk ile bağlantılıdır. Takip talebinde alacak miktarının bitcoin olarak gösterilmesi, ödemenin bitcoinle yapılması, bitcoinin haczi veya tasarrufun iptali davasına konu edilebilmesi icra hukuku bakımından değerlendirilmesi gereken konulardır. Türk hukuku bakımından Bankacılık Düzenleme ve Değerlendirme Kurumu'nun açıklaması gereği, bitcoin elektronik para olarak kabul edilmemektedir. Bu nedenle, bitcoinin 6493 sayılı Ödeme ve Menkul Kıymet Mutabakat Sistemleri, Ödeme Hizmetleri ve Elektronik Para Kuruluşları Hakkında Kanun çerçevesinde gözetim ve denetimini yapılmamaktadır.

Bitcoin'in tüm icra ve iflas hukukunun tamamı üzerindeki etkisi, bu çalışmanın sınırlarını aşacak niteliktedir. Takip talebinde bitcoinin gösterilmesi, bitcoin ile ödeme, bitcoinin haczi gibi konular ayrı birer çalışmanın konusu olabilecek niteliktedir. Bu çalışmada, bitcoinin ve icra hukuku ilişkisi işaret edilecek; bitcoinin takip talebi, ödeme aracı, haciz, satış ve tasarrufun iptali davası bakımında etkileri genel olarak değerlendirilecektir.

\section{GENEL OLARAK BITCOIN}

Bitcoin, 2008 yılında Satoshi Nakamato tarafından yaratılan, iki tarafin merkez bankası ya da herhangi bir üçüncü bir güvenilir kişiye ihtiyaç duymadan doğrudan doğruya birbirileriyle işlem yapabileceği bir elektronik ödeme sistemidir ${ }^{6}$. Kullanıcıların, bitcoin olarak adlandırılan elektronik ödeme sistemi ile işlem yapabilmesi için öncelikle şifreli bir şekilde oluşturulmuş sanal cüzdana sahip olmaları gerekmektedir. Bitcoinler oluşturulmuş olan bu sanal cüzdanlarda muhafaza edilmekte, oluşturulan bu sanal cüzdanlarda bulunan bitcoin miktarları ile kullanıcıların tüm hareketleri block chain (blok zinciri) olarak adlandirılan sanal defterlere kaydedilmektedir.

Bitcoin üretim işlemine madencilik adı verilmektedir. Bitcoin madenciliği ise bilgisayarın özelliği olan bir sayıyı arayıp bulması olarak ifade edilmektedir. Madencilik faaliyeti ilk zamanlarda işlemci tabanlı olmasına karşın daha sonra yerini ekran kartlarının kullanıldığı madenciliğe bırakmıştır ${ }^{7}$. Bitcoin madenciliğine olan ilgilinin artması, bitcoine hâkim olan protokol sebebiyle, özellikli sayıyı bulmayı zorlaştırmış ve madencilik faaliyetinde ekran kartlarının kullanılması madencilik faaliyetlerindeki verimliliği azaltmıştır.

\footnotetext{
${ }^{6}$ Nakamato, s. 28.

${ }^{7}$ http://coin-turk.com/bitcoin-madencili-nedir-ve-nasil-yapilir (22.01.2018).
} 


\section{BITCOIN VE İCRA HUKUKU}

Günümüzde ise bitcoin madenciliği uygulamaya özgü tümleşik devrelerin ${ }^{8}$ kullanılması (ASIC) ile fayda sağlayabilecek zorluğa ulaşmıştır.

Bitcoin'in en büyük avantajlarından biri, herhangi bir otoriteye bağlı olmamasıdır. Bununla birlikte kullanıcıların herhangi bir aracı kuruma ihtiyaç duymadan bitcoin alışverişinde bulunmaları işlem kolaylığını da beraberinde getirmektedir. Ancak bu kolaylık beraberinde güvenlik sorununu ortaya çıkarmaktadır. Bitcoin sisteminde güvenlik, djital imzalarla sağlanmaktadır. Dijital imzaların doğruluğunun kontrolü, sistemde kayıtlı diğer kullanıcıların dijital imzalarının teyidi ile yapılmaktadır. Her imzanın ilişkili olduğu bir gönderici adresi bulunmasıyla sistemde kayıtlı adresler arasında gerçekleşen transfer güvenli hale gelmektedir 9 . Bitcoin faaliyetlerinin merkezi bir otoriteye bağlı olmaması bu sistemin kara para aklanması ve terörün finansmanı gibi faaliyetlerde sıkça kullanılması sonucunu doğuracaktır.

\section{BITCOIN'INN HUKUKÎ NITTELİ̆̈̇}

Bitcoin kullanımının yaygınlaşması bu işlemlerin vergilendirmeye tâbi tutulması tartışmalarını da beraberinde getirmektedir ${ }^{10}$. Ancak vergi kanunlarına göre bir kazançtan vergi alınabilmesi için o kazancın adının konulması gerekir" ${ }^{11}$. Bu sebeple bitcoinin "emtia"12, "menkul kıymet" ya da "para" olarak adlandırılabileceği konusunda çalışmalar yürütülmektedir ${ }^{13}$. Bitcoinin emtia olarak adlandırılması elde edilen kazanç sonucunda gelir vergisi ve katma değer vergisi ödenme ihtimalini ortaya çıkaracaktır.

Bitcoin bir ödeme aracıdır ${ }^{14}$; bitcoinin hukukî niteliği bakımından mevduat, havale, para ve sözleşme kaynaklı borç ilişkisi olmak üzere dört görüş bulunmaktadır ${ }^{15}$. Öğretide

\footnotetext{
${ }^{8}$ Smith/Sebastian, s.

${ }^{9}$ Bozdanoğlu, s. 6; Selçuk, s. 68-69.

10 “...Bitcoin madencilerinin vergi kanunlarımız karşısındaki durumu bir imalatçıdan farksız olmaktadır. Bu faaliyetleri nedeniyle oluşan kazançları ticari kazanç veya kurum kazancı olarak vergiye tabi olup, bunların Türkiye'de gerçekleştirdikleri bitcoin teslimleri de KDV'ye tabi olacaktır..." https://www.dunya.com/koseyazisi/bitcoinin-vergilendirilmesi/395306 (24.01.2018).

${ }^{11}$ https://www.ntv.com.tr/teknoloji/bitcoine-vergi-geliyor-maliye-spk-ve-mb-kripto-paralari inceliyor,riHhA6CgEUqJgGXs7RWlgA (19.01.2018).

${ }^{12}$ Merkez Bankası ve SPK'nın tutumu Türkiye'nin kripto parayı bir emtia olarak kabul edeceği işaretlerini güçlendiriyor. Gelir İdaresi Başkanı Adnan Ertürk de Kanada örneğini vererek bu ülkenin Bitcoin'i bir emtia olarak gördüğünü ifade etmektedir..." https://www.cnnturk.com/ekonomi/turkiyede-bitcoinden-para-kazanangelir-vergisi-ve-kdv-odeyebilir (24.01.2018).

${ }^{13} \mathrm{http}: / /$ www.haberturk.com/maliye-bakanligi-spk-merkez-bankasi-bitcoini-gozaltina-aldi-1752477-ekonomi 19.01.2018).

${ }_{15}^{14} \mathrm{http}$ ///www.milliyet.com.tr/yazarlar/prof-dr-erol-ulusoy/bitcoin-hukuken-nedir--2573460/ (24.01.2018).

15 Bitcoinin hukukî niteliğine ilişkin bkz. Önal, s. 183-189.
} 


\section{BITCOIN VE İCRA HUKUKU}

bitcoin faaliyetinde yer alan kişilerin (kullanıcılar, madenciler ve madencilere maddi destekte bulunan kişiler) aralarındaki ilişkinin mevcut özel hukuk hükümleri çerçevesinde sözleşmesel olarak değerlendirilmesi gerektiği ifade edilmektedir ${ }^{16}$. Öğretide, bitcoinin elektronik paranın özel bir şekli olduğu yönünde görüş de bulunmaktadır ${ }^{17}$.

Avrupa Adalet Divan1, 22.10.2015 tarih ve C-264/14 say1lı kararıla bitcoini sanal para olarak kabul etmiştir. İlgili karar, İsveç Vergi İdaresi ile internet üzerinden bitcoin alıp satacak, aracılık edecek bir işletme kurmak isteyen David Hedqvist adlı İsveç vatandaşı arasında, bitcoinin KDV'ye tabi olup olmadığı noktasında ortaya çıkmıştır. Avrupa Adalet Divanı, önce konvansiyonel bir para ödeyerek bitcoin satın almanın Avrupa Birliği Katma Değer Vergisi Direktifleri'nin özellikle 135'inci maddesi kapsamında KDV'den muaf olduğuna karar vermiştir. Bitcoinin sonradan konvansiyonel paraya dönüştürülmesi esnasında elde edilecek değer artışının da KDV'den muaf olduğuna, çünkü bitcoin'in sanal bir para olduğuna hükmetmiştir ${ }^{18}$.

\section{BITCOIN VE TÜRK HUKUKU}

Teknolojinin hızlı bir şekilde gelişmeye devam etmesi devletleri bu konuda yeni hukukî düzenlemeler yapmaya itmektedir ${ }^{19}$. Ödeme ve Menkul Kıymet Mutabakat Sistemleri, Ödeme Hizmetleri ve Elektronik Para Kuruluşları Hakkındaki Kanunu 27.06.2013 tarihli Resmî Gazetede yayınlanmıştır. Bu kanun, ödeme ve menkul kıymetler sistemi üzerinden işlem yapan birimlerin kurulmasına imkân tanımıştır. Bu Kanunun ardından, 2013 yılının Temmuz ayında, Türkiye'de ilk bitcoin, Türk bitcoin borsasının açılması ile tedavüle girmiştir. 2013 yılından itibaren Türk lirası karşılığında bitcoin alım satım işlemleri yapılmaktadır ${ }^{20} .2018$ yılı itibariyle 1 bitcoin karşılığı, 42.892 .70 TL Türk lirasıdır ${ }^{21}$.

Türk hukukunda "bitcoin" ile ilgili henüz bir düzenleme bulunmamakla birlikte, bitcoinin 5237 sayılı Türk Ceza Kanunu'nun 141 ve devamındaki maddelerde düzenlenen hırsızlık suçunun maddî konusunu oluşturacağı bir gerçektir ${ }^{22}$. Bununla birlikte hileli

\footnotetext{
${ }^{16}$ Önal, s. 189-190; http://www.kasaroglu.av.tr/tr/bitcoin-ve-diger-sanal-para-birimleri (19.01.2018).

${ }^{17}$ Schmid/Schmid, s. 2.

${ }^{18}$ http://www.milliyet.com.tr/yazarlar/prof-dr-erol-ulusoy/bitcoin-hukuken-nedir--2573460/ (24.01.2018).

${ }_{19}$ Çeşitli ülkelerin bitcoine bakışı için bkz. Önal, s. 171-174.

20 Önal, s. 174-175.

${ }^{21} \mathrm{http}: / /$ bitcoin.tlkur.com/ (22.01.2018).

22 “...zanlıların, bitcoinlerini kendi hesaplarına aktarabilmek için maktulün parmağını cep telefonunun parmak izi okuyucusuna tuttukları ancak güvenlik duvarını aşamadıkları tespit edildi..." (http://www.hurriyet.com.tr/bitcoin-cinayetinde-sok-detaylar-40582766 24.010.2018).
} 


\section{BITCOIN VE İCRA HUKUKU}

davranışlarla bir başkasına ait bitcoinlerin ele geçirilmesi sonucunda kişisinin kendisine veya bir başkasına bir yarar sağlaması dolandırıcılık suçunun (TCK m. 157) oluşmasına sebep olacaktır ${ }^{23}$.

Bitcoin’e ilişkin olarak Türk hukukunda özel bir düzenleme bulunmamaktadır. Ancak elektronik paraya ilişkin olarak, 6493 sayılı Ödeme Ve Menkul Kıymetler Mutabakat Sistemleri, Ödeme Hizmetleri Ve Elektronik Para Kuruluşları Hakkında Kanun söz konudur. Bu Kanun'da elektronik para tanımlanmaktadır; buna göre elektronik para, “Elektronik para ihraç eden kuruluş tarafindan kabul edilen fon karşılliğı ihraç edilen, elektronik olarak saklanan, bu Kanunda tanımlanan ödeme işlemlerini gerçekleştirmek için kullanılan ve elektronik para ihraç eden kuruluş dışındaki gerçek ve tüzel kişiler tarafindan da ödeme aracı olarak kabul edilen parasal değer” olarak değerlendirilmektedir. Elektronik para kuruluşu ise, “Bu Kanun kapsamında elektronik para ihraç etme yetkisi verilen tüzel kişi”dir.

Bitcoinlerin elektronik para olup olmadığına ilişkin olarak 25 Kasım 2013 tarihinde Bankacılık Düzenleme ve Değerlendirme Kurumu bir açıklama yayınlama gereği duymuştur. $\mathrm{Bu}$ açıklama "Herhangi bir resmi ya da özel kuruluş tarafindan ihraç edilmeyen ve karşılı̆̆ için güvence verilmeyen bir sanal para birimi olarak bilinen Bitcoin, mevcut yapıst ve işleyişi itibarlyla Kanun kapsamında elektronik para olarak değerlendirilmemekte, bu nedenle de söz konusu Kanun çerçevesinde gözetim ve denetimi mümkün görülmemektedir.” şeklindedir ${ }^{24}$. Bankacılık Düzenleme ve Değerlendirme Kurumu, bitcoinin gözetim ve denetiminin mümkün olmadığını, sistemde kimliklerin bilinmemesi nedeniyle yasadışı faaliyetlere açık olduğunu, değerinin sürekli değiştiği ve risklere açık olduğunu ifade etmektedir ${ }^{25}$. Sonuç olarak Türk hukuku bakımından Bankacılık Düzenleme ve Değerlendirme Kurumu'nun açıklaması gereği bitcoin elektronik para olarak kabul edilmemektedir. Bu nedenle bitcoinin 6493 sayılı Ödeme ve Menkul Kıymet Mutabakat Sistemleri, Ödeme Hizmetleri ve Elektronik Para Kuruluşları Hakkında Kanun çerçevesinde gözetim ve denetimini yapılmamaktadır ${ }^{26}$.

$\mathrm{Bu}$ noktada bitcion'in elektronik para olup olmadığının değerlendirilmesi gerekir. Bitcoin ihraç eden kişiler, mining faaliyeti yürüten miner'lardır; minerlerin ise, tüzel kişiliği

\footnotetext{
${ }^{23}$ Bitcoin ve kamu hukuku yakın ilişki içindedir. Bitcoin ve kamu hukuku ilişkisi için bkz. Schmid/Schmid, s. $5-7$.

${ }^{24}$ https://www.bddk.org.tr/websitesi/turkce/Duyurular/Basin_Aciklamalari/12574bitcoin_hk_basin_aciklamasi.p df (19.01.2018).

$\frac{\mathrm{d}}{25}$ Selçuk, s. 72 .

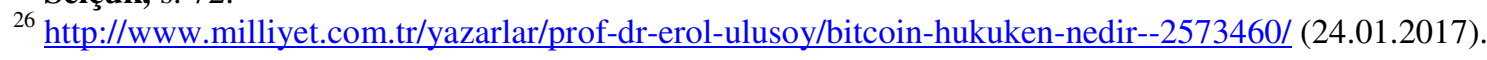




\section{BITCOIN VE İCRA HUKUKU}

bulunmamaktadır. Bu nedenle minerlerin elektronik para kuruluşu olarak kabulü mümkün değildir. Herhangi bir kurum, kuruluş veya kişiye bağlı olmayan bitcoin elektronik para olarak nitelendirileme $\mathrm{z}^{27}$.

\section{BITCOIN'İN İCRA HUKUKU BAKIMINDAN DEĞERLENDİRILMESİ}

Kullanıma dair yasal bir çerçeve bulunmayan bitcoin, 2013 yılından itibaren Türkiye'de kullanılmaktadır. Vergi veya ceza hukuku gibi kamu hukuku alanları ile doğrudan bağlantısı bulunan bitcoin, icra hukuku bakımından da önem arz etmektedir. Bilindiği üzere alacaklı, takip talebinde alacak tutarını açık ve net olarak göstermelidir. Alacaklı, takip talebinde, talep ettiği para alacağının Türk parası ile tutarını göstermelidir. Alacak yabancı para alacağı ise, alacaklının yabancı para alacağını vade veya takip tarihindeki döviz kuru üzerinden Türk parasına çevirmesi ve Türk parası üzerinden takip yapması gerekir ${ }^{28} . \mathrm{Bu}$ anlamda alacaklı, takip talebinde bitcoini para birimi olarak kullanamayacaktır. Zira şu an için bitcoin Türk hukuku bakımından kabul edilmiş bir para birimi veya elektronik para niteliğinde değildir. Bitcoin olarak belirlenmiş alacağın, takip talebinde Türk Lirası olarak gösterilmesi gerekecektir. İsviçre'de de takip talebinde alacak miktarının bitcoin olarak gösterilmesinin mümkün olmadığı, alacak miktarının İsviçre para birimi (SchKG Art. 67 Abs. 1) ile gösterilmesi gerektiği ifade edilmektedir ${ }^{29}$.

İcra dairesine yapılacak ödemeler bakımından da bitcoinin değerlendirilmesi gerekir. İcra dairesine ödeme, icra dairesinin olumlu yükümlülüklerinden biri olarak ifade edilmektedir $^{30}$. 6352 sayılı Kanunla İcra ve İflâs Kanunu'nda yapılan değişiklik gereğince, icra-iflâs dairelerine yapılacak her türlü nakdî ödeme Adalet Bakanlığınca uygun görülecek banka hesabına yatırılacaktır. İcra-iflâs memurunun ilgili ödemeleri kabul etme zorunluluğu bulunmamaktadır. Haciz sırasında, borçlu veya üçüncü kişiler tarafından yapılan ödeme nedeniyle tahsil edilen paralar, en geç tahsilatın yapıldığı günü takip eden ilk iş günü çalışma saati sonuna kadar banka hesabına yatırılmak üzere icra veya mahkeme kasalarına muhafaza edilir. İcra ve iflas dairelerince yapılması gereken her türlü nakdî ödeme, ilgilisinin gösterdiği banka hesabına aktarılmak üzere, icra müdürü tarafından re'sen bankaya verilecek talimat gereği yapılır. Talimat, paranın icra ve iflas dairesi hesabına yatırılmasını takip eden en geç üç

\footnotetext{
${ }^{27}$ Bayülken, s. 4. Aksi görüş için bkz. Önal, s. 184.

${ }^{28}$ Kuru, s. 198.

${ }^{29}$ Schmid/Schmid, s. 8.

${ }^{30}$ Kuru, s. 83 vd.; Pekcanıtez/Atalay/Sungurtekin-Özkan/Özekes, s. 84 vd.
} 


\section{BITCOIN VE İCRA HUKUKU}

iş günü sonuna kadar verilir (İIK m. 9). Haciz sırasında borçlu veya üçüncü kişi tarafından ödeme yapılırsa bu para istisna olarak alınabilir. Ancak en geç tahsilatın yapıldığı günü takip eden ilk iş günü çalışma saati sonuna kadar banka hesabına yatırılmak üzere icra veya mahkeme kasalarında muhafaza eder $^{31}$. İcra hukukunun amac1, takip konusu borcun ödenmesidir. Bu nedenle bitcoin, icra hukukunun amacının gerçekleştirilmesi bakımından önem arz etmektedir ${ }^{32}$. Kuru, ödemelerin sadece para ile yapılabileceğini; çek, teminat mektubu gibi ödeme araçlarının ödeme yerine geçmeyeceğini ifade etmektedir. Burada para ile ifade edilmek istenen Türk parasıdır. Yabancı para ile yapılan ödemelerin İcra ve İflâs Kanunu anlamında ödeme olarak kabul edilmediği belirtilmektedir ${ }^{33}$. Elektronik para niteliğinde olmayan, herhangi bir kurum, kuruluş veya kişiye bağlı olmayan bitcoin, icra hukuku bakımından bir ödeme aracı olarak kabul edilemeyecektir. Takip konusu borcun bitcoin olarak ödenmek istenmesi halinde, bu talep kabul edilmeyecektir. Bitcoinle ödeme talebinin reddi de, şikâyete konu edilemeyecektir. İsviçre'de de bitcoin, kanunî bir ödeme aracı niteliğine sahip değildir ${ }^{34}$.

Genel haciz yoluyla takip; takip talebi, ödeme emri, ödeme emrine itiraz, takibin kesinleşmesi, haciz, satış ve paraların ödenmesi aşamalarından oluşmaktadır. Takip kesinleşmesine rağmen, borçlu borcunu ödemezse alacaklı haciz talep edebilir. Haczin konusunu borçlunun taşınır ve taşınmaz malları, üçüncü kişideki alacakları ve diğer malvarlığı hakları oluşturmaktadır. Para, taşınır mal olarak kabul edilmektedir. Para, taşınır malların haczine ilişkin hükümler gereğince haczedilmektedir. Taşınır malların haczinde icra müdürünün bu mallara fiilen el koyması şart değildir; ancak para gibi bazı taşınırlar da hukukî ve fiilî haciz aranmaktadır. Borçlunun elinde haczedilen para, icra dairesi tarafından muhafaza edilmektedir (İ̈K m. 88/I ve m. 9).

Anonim ve takip edilemez olmaları nedeniyle devletin bitcoinlere ulaşımı çok zordur $^{35}$. Elektronik para niteliğinde olmayan, herhangi bir kurum, kuruluş veya kişiye bağlı olmayan bitcoinin taşınır eşya olarak fiilen haczedilemez. Bitcoin, icra hukuku bakımından hak olarak kabul edilerek hukuken haczedilebilir; ancak bitcoinin fiilen haczedilebilmesi mümkün değildir.

\footnotetext{
${ }^{31}$ Pekcanıtez/Atalay/Sungurtekin-Özkan/Özekes, s. 86-87.

${ }^{32}$ Schmid/Schmid, s. 7.

${ }^{33}$ Kuru, s. 88.

${ }^{34}$ Schmid/Schmid, s. 7-8.

${ }^{35}$ Bayülken, s. 3.
} 


\section{BITCOIN VE İCRA HUKUKU}

Bilindiği üzere icra hukuku bakımından hacizden önce borçlunun mal ve hakları üzerinde tasarruf yetkisi bakımından kural olarak, bir sınırlama bulunmamaktadır. Bu nedenle borçluların alacaklılarından mal kaçırmak amacıyla çeşitli hileli işlemler yaptıkları görülmektedir. Kanun koyucu, haciz veya iflâstan önce borçlunun, bağışlamalar ve şüpheli tasarruflarının iptali için iptal davasını düzenlemiştir (İIK m. 277-284). Buna göre; ivazsız tasarruflar (İ̈K m. 278), aciz halinde yapılan tasarruflar (İ̈K m. 279) ve hileli tasarruflar (İ̈K m. 280) iptal davasına konu olmaktadır. Borçlu tarafından bitcoinle tasarrufun iptali davasına konu olabilecek işlemler yapılabilir ve alacaklılar zarara uğratılabilir. Ancak bitcoin tasarrufun iptali davasına konu olsa bile, anonim ve takip edilemez olması nedeniyle sonuç elde edilemeyecektir.

\section{SONUÇ}

Bitcoin, 2008 yılında ortaya çıkmıştır. İlgililerin merkez bankası ya da herhangi bir üçüncü kişiye ihtiyaç duymadan doğrudan doğruya birbirileriyle işlem yapabileceği bir elektronik ödeme sistemi olarak ifade edilmektedir. Bitcoinin hukukî niteliğinin emtia, menkul kıymet veya para olduğuna dair tartışmalar bulunmaktadır.

Türk hukuku bakımından Bankacılık Düzenleme ve Değerlendirme Kurumu, bitcoini elektronik para olarak kabul etmemektedir. Bu nedenle, bitcoinin 6493 sayılı Ödeme ve Menkul Kıymet Mutabakat Sistemleri, Ödeme Hizmetleri ve Elektronik Para Kuruluşları Hakkında Kanun çerçevesinde gözetim ve denetimi yapılmamaktadır. Bitcoin, şu aşamada Türk hukuku bakımından tanınmayan ve korunmayan bir paradır.

Vergi veya ceza hukuku gibi kamu hukuku alanları ve özel hukukla bağlantısı bulunan bitcoin, icra hukuku bakımından da önem arz etmektedir. Takip talebinde alacak miktarının bitcoin olarak gösterilmesi mümkün değildir. Takip talebinde alacak miktarının Türk Lirası olarak gösterilmesi gerekir. İcra hukuku bakımından ödemeler, sadece para ile yapılabilir; burada para ile ifade edilen, Türk parasıdır. Elektronik para niteliğinde olmayan, herhangi bir kurum, kuruluş veya kişiye bağlı olmayan bitcoin, icra hukuku bakımından bir ödeme aracı olarak kabul edilemez. Elektronik para niteliğinde olmayan, herhangi bir kurum, kuruluş veya kişiye bağlı olmayan bitcoin taşınır eşya olarak haczedilemez. Bitcoinin, icra hukuku bakımından hak olarak kabul edilerek hukuken haczedilebileceği düşünülebilse de; fiilen haczedilebilmesi mümkün değildir. Bitcoin, tasarrufun iptali davasına konu olabilir. Ancak bitcoin tasarrufun iptali davasına konu olsa bile, anonim ve takip edilemez olması nedeniyle 


\section{BITCOIN VE İCRA HUKUKU}

sonuç elde edilemeyecektir. Bu nedenle bitcoin, kötü niyetli borçluların elinde alacaklilar zarara uğratabilecek bir araç haline gelebilir.

Bitcoin, hukuk düzeni tarafindan korunmayan bir para olmakla birlikte, kullanımı yaygındır. Bitcoin, birçok hukukî sorunu da beraberinde getirmektedir. Hukuk düzeninin bitcoinden uzak duramayacağı açıktır.

\section{KAYNAKÇA}

BAYÜLKEN Kaan, Bitcoin, Kriptografi ve Anonimlik Hakkı (https://www.academia.edu/28616587/BITCOIN_KR\%C4\%B0PTOGRAF\%C4\%B0_VE _ANON\%C4\%B0ML\%C4\%B0K_HAKKI 20.12.2017).

BOZDANOĞLU Burçin, Sanal Para Bitcoin'in Kayıtdışı Ekonomi ve Kara Para Faaliyetlerine Etkisi ve Vergilendirilmesi, Legal Mali Hukuk Dergisi, Cilt 10, Sayı 111, 2014.

KURU Baki, İcra ve İflas Hukuku El Kitabı, 2. Bask1, İstanbul 2013.

NAKAMATO Satoshi, Bitcoin: A peer-to-peer electronic cash system, 2008.

ÖNAL Ali, Banka Vasıtalı Ödeme Araçlarını Dışlayan Bir Sistem Olarak Kripto Sanal Para Bitcoin ve Hukuki Niteliği, Legal Banka ve Finans Hukuku Dergisi, Cilt 5, Sayı 17, 2016.

PEKCANITEZ Hakan, ATALAY Oğuz, SUNGURTEKİN ÖZKAN Meral ve ÖZEKES Muhammet, İcra ve İflâs Hukuku Ders Kitabı, 2. Bask1, Ankara 2015.

SCHMID Jean Daniel und SCHMID Alexander, Bitcoin eine Einführung in die Funkionsweise sowie eine Auslegeordnung un derste Analyse möglicher rechtlicher Fragestelleung, In Jusletter 4, Juni, 2012.

SELÇUK İsmail Veysel, Yeni Fenomen Bitcoin, Üstad Avukatllk Meslek Dergisi, Kış 2018.

SMITH Michael and SEBASTIAN John, Application-specific integrated circuits, Vol. 7. Reading, MA, Addison-Wesley, 1997.

http://bitcoin.tlkur.com/ (22.01.2018). 


\section{BITCOIN VE İCRA HUKUKU}

http://coin-turk.com/bitcoin-madencili-nedir-ve-nasil-yapilir $(21.01 .2018)$.

http://www.haberturk.com/maliye-bakanligi-spk-merkez-bankasi-bitcoini-gozaltina-aldi1752477-ekonomi ( 19.01.2018).

http://www.haberturk.com/turkiye-ye-bitcoin-ile-bugday-dunyada-bir-ilk-1808541ekonomi (24.01.2018).

http://www.hurriyet.com.tr/bitcoin-cinayetinde-sok-detaylar-40582766 (24.010.2018).

http://www.kasaroglu.av.tr/tr/bitcoin-ve-diger-sanal-para-birimleri (19.01.2018).

http://www.milliyet.com.tr/yazarlar/prof-dr-erol-ulusoy/bitcoin-hukuken-nedir--2573460/ (24.01.2018).

https://www.bddk.org.tr/websitesi/turkce/Duyurular/Basin_Aciklamalari/12574bitcoin_hk _basin_aciklamasi.pdf (19.01.2018).

https://www.cnnturk.com/ekonomi/turkiyede-bitcoinden-para-kazanan-gelir-vergisi-vekdv-odeyebilir (24.01.2018).

https://www.dunya.com/kose-yazisi/bitcoinin-vergilendirilmesi/395306 (24.01.2018).

https://www.ntv.com.tr/teknoloji/bitcoine-vergi-geliyor-maliye-spk-ve-mb-kripto-paralari inceliyor,riHhA6CgEUqJgGXs7RWlgA (19.01.2018). 